\title{
REPRESENTAÇÕES HISTORIOGRÁFICAS CATÓLICAS POR OCASIÃO DA COMEMORAÇÃO DO IV CENTENÁ́RIO DA CIDADE DE SÃO PAULO
}

\author{
Damião Duque de Farias \\ Doutorando em História Social FFLCH-USP \\ Prof. de História do Brasil - UFMS
}

\section{Resumo}

Esse artigo é fruto da leitura do livro A Igreja dos Quatro Séculos de São Paulo - 1554-1954. Verificamos que em primeiro lugar, este livropossui, em sua análise histórica, as características da historiografia e das representações do passado da elite paulista: o espírito bandeirante e a vocação nacional dos paulistas. Assim, constitui-se um passado católico em São Paulo relacionado com a seleção dos momentos e de determinados elementos históricos, recaindo a preferência sobre a presença dos jesuítas em terras paulistas na primeira fase colonial e sobre a fundação oficial da cidade de São Paulo. Nos demais períodos, são escolhidos os fatos e atores que não chocam a representação geral que, entre outras coisas, procura mostrar a força perene da religiosidade católica em terras paulistas e brasileiras.

\section{Pallavras-Chave}

Historiografia • Representações • Bandeiras • Catolicismo • Jesuítas

\section{Abstract}

This article results from a critical reading of the book A Igreja dos Quatro Séculos de São Paulo - 1554-1954. In its historical approach, this book expresses two characteristics of a historiography and representation of the past associated with São Paulo's elite: the bandeirante spirit and the Paulistas' role in shaping the nation. The book constructs São Paulo's Catholic past in relation to a selection of specific historical moments and elements, emphasizing the presence of Jesuits during the early colonial period and especially their role in the official establishment of the city. During subsequent periods, this approach selects facts and actors that do not contradict the general representation, which seeks to show the perennial force of Catholicism in São Paulo and in Brazil.

\section{Keywords}

Historiography $\bullet$ Representation $\bullet$ Expeditions $・$ Catholicism • Jesuits 


\section{Texto e Contexto}

Neste ensaio bibliográfico analisaremos a obra A Igreja dos Quatro Séculos de São Paulo - 1554-1954, composta no ano dos festejos do IV Centenário da capital paulista e publicada pela Editora Documentários Nacionais Ltda. em 1955. O volume traz uma coletânea de textos (alguns originais e outros não) de vários autores pertencentes ao Instituto Histórico e Geográfico de São Paulo (entre eles, Enzo Silveira), à Academia Paulista de Letras (por exemplo, J. P. Leite Cordeiro) e à própria Igreja Católica (vide o Cônego Luiz Castanho de Almeida). Escritores filiados a outras entidades literárias e científicas também figuram, em menor número, no crédito dos autores ${ }^{1}$.

Podemos, com alguma liberdade, dividir o conjunto dos artigos apresentados na obra a ser analisada em dois grupos: o primeiro empreende uma análise histórica e simbólica da presença da Igreja na cidade de São Paulo e, por extensão (como veremos), no Estado de São Paulo e no Brasil. Esse grupo é constituído por dois subgrupos: um composto pelos cinco primeiros artigos e o décimo primeiro, intitulado "A Igreja em São Paulo, no Período Imperial”, de autoria do Cônego Luiz Castanho de Almeida, e o outro constituído por outros nove artigos, que compõem um quadro simbólico da presença da instituição católica em São Paulo, apresentando resumos biográficos, dados genealógicos, símbolos oficiais, etc. O artigo do Cônego Luiz Castanho de Almeida, isolado dentre os artigos que compõem o primeiro subgrupo, demonstra, como observaremos, uma leitura, consciente ou inconsciente, da história da Igreja em São Paulo.

O segundo grupo é composto de três partes: da primeira consta uma relação de lugares públicos que receberam nomeação católica; a segunda refere-se às igrejas e capelas da cidade de São Paulo; quanto à terceira, alude às paróquias da Arquidiocese de São Paulo e ao trabalho social e religioso desenvolvido por elas. Parece-nos que a intenção geral desse segundo grupo é demonstrar o gigantismo da estrutura, a força e o trabalho da Igreja a acompanhar o desenvolvimento da grande metrópole brasileira, uma cidade que carrega consigo certos símbolos ligados ao trabalho, ao desenvolvimento, à modernidade.

\footnotetext{
${ }^{1}$ O exemplar por nós analisado encontra-se no Arquivo D. Duarte Leopoldo e Silva, da Cúria Metropolitana de São Paulo. Nele há uma nota introdutória de D. Carlos Carmelo de Vasconcello Motta, então Arcebispo de São Paulo, aprovando elogiosamente a publicação da obra.
} 
Neste trabalho, focaremos nossa análise apenas nos textos que tratam diretamente da presença católica na história paulista e brasileira, compondo uma narrativa historiográfica.

Para fundamentar nossa leitura, pareceu-nos interessante levantar alguns elementos do contexto no qual está inserido nosso objeto de análise. Evidentemente o primeiro desses elementos são as comemorações do IV Centenário da cidade de São Paulo, ocorridas em 1954. Nesse sentido, podemos considerar que A Igreja dos Quatros Séculos de São Paulo: 1554-1954 é também uma obra comemorativa, festiva. Possivelmente esse elemento suscitou uma análise histórica da presença da Igreja em São Paulo mais gloriosa do que crítica. Com essa afirmação, deixamos claro a presença de um certo valor relativo, haja vista que a análise contida na obra em questão foi uma iniciativa da hierarquia, cuja visão histórica até então estivera conformada pelos valores heróicos e positivos que marcaram (e marcam) parte de nossa historiografia.

As festividades do IV Centenário têm sua importância realçada quando consideramos que sobre o nascimento da cidade paira a iniciativa do Padre Manuel da Nóbrega, considerado o primeiro grande nome da Igreja Católica em terras paulistas e brasileiras. Nesse sentido, a hierarquia católica, acompanhada pela "Legião de São Paulo Pró-Catedral”, reuniu todos os esforços com o fito de, na data considerada como a do IV Centenário da fundação da cidade, ou seja, em 25 de janeiro de 1954, inaugurar a nova Catedral da Sé, após décadas de trabalho de construção. Com esse ato pretendiam não só relembrar a atuação de Nóbrega 400 anos antes, mas também marcar a importância e a presença católica na cidade de São Paulo. No Boletim Eclesiástico da Arquidiocese de São Paulo, de janeiro de 1954, lemos o seguinte:

(...) a vida religiosa, humildemente começada na igrejinha de palha do Pátio do Colégio em 25 de Janeiro de 1554 e que vai manifestar-se esplendorosamente, 400 anos depois, neste 25 de janeiro de 1954, na magnífica e imponente Catedral do Largo da Sé, para a maior glória de Deus.

A inauguração da Nova Catedral será o fato culminante das comemorações religiosas do IV Centenário de São Paulo.(...)

Conta agora a Arquidiocese com uma Sé à altura de sua grandeza material e espiritual. Não nos precisamos deter sobre o valor artístico e monumental da Nova Catedral. Aí está para ser vista e admirada. Se nenhum outro monumento permanecer, marco comemorativo do IV Centenário, será bastante a Catedral. E a púrpura do Príncipe da Igre- 
ja, a dignidade máxima que pode receber uma Diocese, está agora condignamente abrigada em São Paulo.

Envolvendo as comemorações do IV Centenário em 1954, outra "grande obra" seria inaugurada: o Parque do Ibirapuera. Construído a partir da iniciativa dos poderes públicos, o Parque deveria ser símbolo da metrópole cosmopolita (Exposição Internacional) e de convivência humana, mas antes de tudo deveria ser a representação da "cidade que mais cresce no mundo", como era então o slogan paulistano divulgado na época. Este sentido ficou claramente enunciado no símbolo do IV Centenário, projeto de Oscar Niemeyer. Como sabemos a idéia de crescimento constitui um dos lemas centrais da ideologia dominante no Estado de São Paulo, presente inclusive em sua historiografia.

Outro elemento importante do contexto e que é presença marcante nos textos de análise histórica da Igreja é o catolicismo romanizado, expressão de uma autocompreensão católica surgida com o Concílio tridentino em meados do século passado e que moldou profundas transformações nas diversas práxis católicas em todo o mundo, inclusive no Brasil, quando a hierarquia da Igreja brasileira passou a ter maiores vinculações com a Sé romana e com a ortodoxia.

O movimento de reformas ultramontanas na Igreja Católica brasileira iniciou-se também em meados do XIX, no interior da estrutura eclesiástica. A partir da década de 20 deste século, passou a avançar em direção a outras organizações sociais, inclusive os aparelhos do Estado. Este movimento foi nomeado de neocristandade; seu objetivo: alojar no interior de todas as instituições os valores católicos ${ }^{2}$. A partir do anos 50, o movimento conhecerá uma nova fase, com um novo desafio: conseguir a incorporação daqueles valores por todos os cidadãos que assim contribuiriam para a reforma da sociedade. A chamada Ação Católica e suas várias ramificações, bem como outros movimentos como o Movimento por um Mundo Melhor - MMM, eram considerados os instrumento adequados para tal proposição.

A partir desse momento, ocorreu uma tentativa de levar os fiéis a um processo de internalização deliberada dos valores morais e sociais do catolicismo institucional, o pressuposto para legitimar as concepções e práticas da socie-

\footnotetext{
${ }^{2}$ Ver: FARIAS, Damião Duque de. Em defesa da ordem: aspectos da práxis conservadora católica no meio operário em São Paulo (1930-1945). São Paulo: História Social/ USP, Ed. Hucitec, 1998.
} 
dade moderna no contexto da vida urbana e para intervir na realidade social; configurava-se, assim, nova fase de expansão do catolicismo romanizado. De certa maneira, esse movimento apresentava aos católicos a necessidade de uma espécie de movimento catequético, não mais sobre a população indígena, no entanto, no contexto da atuação da Igreja em São Paulo, sobre a massa da população urbana, enormemente aumentada graças à chegada de migrantes do interior do Estado de São Paulo e de outras regiões do país, especialmente do Nordeste. Embora nomeadamente católica, essa população de migrantes trazia consigo valores e práticas religiosas bastante distantes das concepções romanizadas. Grande desafio para a Igreja que, ao tentar equacioná-lo nas décadas seguintes, provocou transformações no catolicismo brasileiro e mundial ${ }^{3}$.

\section{A análise histórica católica}

Como já referimos no início deste trabalho, são seis os artigos que analisam a história da presença da Igreja na cidade de São Paulo. Levantaremos alguns dos elementos mais importantes da constituição discursiva dessa análise, partindo da idéia da "fundação da cidade".

O mito fundador aparece com destaque na obra analisada, sendo inclusive objeto do primeiro artigo da coletânea, "A fundação de São Paulo", de Enzo Silveira. Tal enfoque deve-se ao contexto comemorativo do IV Centenário, incluindo a inauguração da nova Catedral, mas também porque ele se amalgama com vários outros mitos: da fundação do território, da formação do povo, portanto, da formação da própria nação.

Nos textos analisados, verificamos a presença decisiva de Manuel da Nóbrega na fundação de São Paulo em 25 de janeiro de 1554, data da comemoração da conversão do Apóstolo Paulo, considerado também o "Apóstolo dos gentios”. Outras figuras, como João Ramalho, Leonardo Nunes, José de Anchieta, são desqualificados enquanto fundadores da cidade. A fixação de 25 de janeiro de 1554 também torna-se definitiva como data de fundação da cidade e a construção do Colégio é o momento inaugural.

\footnotetext{
${ }^{3}$ Conf. FARIAS, Damião Duque de. Crise e renovação na Igreja Católica em São Paulo: impasses do progressismo e permanências do conservadorismo (1945-1975). Tese de Doutorado, FFLCH-USP, 2002.
} 
Segundo o artigo de Silveira, Nóbrega teria escolhido pessoalmente o lugar no planalto piratininga para o início da "formosa povoação", determinando que ali fosse construído um colégio favorável à catequese. Sua escolha obedeceria a uma visão estratégica de defesa contra possíveis ataques de indígenas inimigos: "Da pequena Igreja, colocada à beira dessa escarpa e no ângulo da mais funda das suas reentrâncias, não só se dominava o horizonte donde era possível uma surpresa ou ataque como se podia fazer a polícia da povoação que lhe crescia na vizinhança". Haveria, ainda, um plano missionário estratégico maior a envolver a escolha, também concebido por Nóbrega. A decisão de instalação no planalto ocorreu por motivos de defesa e expansão da fé. Longe do litoral e, portanto, de ataques piratas e da vida desregrada, os jesuítas poderiam fundar uma civilização baseada na moral cristã, dando continuidade à expansão da fé católica contra os "vândalos embuçados com a capa de reformadores":

Enaltecendo os jesuítas, deles disse com grande eloquência, o Padre Américo de Novaes, vulto proeminente da notável Companhia que eram "verdadeiros guardas avançadas do Catolicismo, empenhados na luta gigantesca contra a heresia, não só combatendo-a de frente e desalojando-a dos baluartes em que se acastelara no Velho Mundo, mas vedando-lhe também a entrada nas regiões novamente descobertas, onde penetram para delatar para o domínio da fé, ressarcindo desta arte, na Ásia e na América, os danos que haviam causado à Religião Católica, na Europa, os vândalos embuçados com a capa de reformadores. (A Igreja...1955: 26).

Nóbrega é o responsável pela fundação da cidade de São Paulo; sua representação é vinculada à imagem de Paulo de Tarso, o Apóstolo, a quem a fundação do povoado é dedicada, inclusive recebendo o seu nome. Nóbrega é um guerreiro, um missionário disposto a converter, a catequizar os gentios do Novo Mundo, como fizera o Apóstolo no Velho Mundo. Aliás, nesse imaginário o próprio Apóstolo por vezes é tido como um "grande" bandeirante ${ }^{4}$.

\footnotetext{
4 "Cultuemos o augusto Padroeiro da Cidade. Rendamos nossas homenagens ao preclaro Santo que nos patrocina todas as iniciativas e todos os esforços e quer e sabe e pode mansamente levar-nos à feliz conquista dos nossos destinos - temporais e eternos. Aí o vedes, bem figurado pelo pincel de Edmundo Migliaccio. Dir-se-ia que o artista quis propositadamente darlhe as feições dos nossos audazes "bandeirantes". Talvez porque "bandeirante" ele o foi deveras e no mais alto e lídimo sentido do já consagrado termo." Discruso proferido em 03/05/ 57 na Câmara Municipal de São Paulo por ocasião de inauguração do retrato do Apóstolo São Paulo. Provavelmente proferido por auxiliar imediato de Dom Carlos Carmello Motta.
} 
Como notamos, a presença da Igreja Católica em terras paulistas é marcante e não apenas isto: é fundadora. Por intermédio dos jesuítas, ela está ligada ao Estado, a Roma, à elite (presente com João Ramalho), mas também ao povo gentio, que é educado em nome da Igreja e da Coroa. Tal presença, portanto, é legitimada pela história da cidade, ou melhor, a história da Igreja e da cidade (do Estado de São Paulo e do Brasil?) se confunde; "Durante este período a sua vida e a sua obra constituem a própria história da nossa formação Pátria.”(A Igreja... 1955: 29)

$\mathrm{Na}$ verdade, o destino da "formosa povoação" fora traçado, profetizado por outro "grande jesuíta", o Padre Anchieta:

Mas entre aqueles evangelizadores recém aportados à terras brasílicas figurava um adolescente em quem ocorria o dom da antevisão do futuro através dos séculos. Apontava-lhe a instigação do dom profético, predicado dos eleitos da graça, a consciência daquilo que mais tarde o levaria a tornar pública a sua profecia a saber: aquela humílima fundação da sua Companhia viria representar uma das maiores tarefas realizadas na terra de Santa Cruz e no Novo Mundo.

Aquele taba de choças do cacique Tibiriçá, reservava-se o mais grandioso futuro convertendo-se como afirmaria, o noviço canarino na maior aglomeração do continente Sul Aericano. Em substituição daquele misérrimo altar de taquaras, cobertas de sapé, erguer-se-iam as naves de suntuosa Catedral uma das mais destacadas do mundo católico. (A Igreja... 1955: 29)

De acordo com o texto de Afonso Taunay, intitulado "Quatro séculos paulistanos", a cidade estava destinada a ser grande! Assim, a idéia de crescimento se faz presente. "E o taumaturgo do Brasil provavelmente no mesmo tempo perceberia que à sua humílima casa missionária e as chopanas dela avizinhantes traria o perpassar dos anos a existência de imenso conjunto de enormes edifícios de arquitetura a mais arrojada e variada num vulto incomparavelmente maior do que o das maiores capitais do seu mundo quinhentista ...". (A Igreja... 1955:35)

Ao finalizar seu artigo, Taunay nos remete novamente à idéia de progresso, patriotismo paulistano, religiosidade, grandiosidade e glorificação: "Permita Deus que a comunidade paulistana inspirada no mote do seu brasão de armas, caminhe sempre pela via da honra de seu governo e do progresso moral, intelec- 
tual, material para maior renome da Nação em cuja história seus filhos inscreveram numerosos e tão gloriosos florões por vezes repassadas da maior grandiosidade." (A Igreja... 1955: 43).

Vejamos um trecho de "Súmula História de Quatro Séculos" de Antonio de Arruda Camargo:

Plantando o Colégio no cimo da Colina dominada pelo Anhangabaú e pelo Tamanduateí, começou o frade a catequese do índio. Subindo e descendo diariamente as suas íngremes ladeiras, alongava cada vez mais o raio de ação de suas atividades. Não era possível contentar-se com o domínio do Colégio, ignorando-se o que havia além dessas praias ribeirinhas. E assim desceu ao Tietê, desceu mais até Pinheiros, traçando um grande círculo que, possivelmente, abrangia o Jaraguá. Quanto, porém, aumentava o casario do Burgo, ao redor dos muros do Colégio, mais urgente se tornava a ampliação do círculo, cujo epicentro era a própria Casa de Piratininga, de onde emanavam todas as forças, todo o entusiasmo daquele movimento que se expandia nas quatro direções. (A Igreja... 1955:61)

Na imagem construída sobre as atividades de Nóbrega, confunde-se a São Paulo de 1554 com a metrópole do IV Centenário, dado o ritmo, as distâncias, o crescimento. Não podemos esquecer que na década de 50 o antigo Centro não perdeu sua importância completamente.

O missionário Manuel da Nóbrega também é considerado o "Gigante da Colonização". De acordo com a análise histórica empreendida pelos textos ora estudados, o trabalho do jesuíta faria parte das intenções e ações da Coroa portuguesa, personificada na figura de Dom João III, o "rei Povoador". Este, ao lançar as bases para a colonização do Brasil, estabeleceu que não haveria "distinção entre europeus e aborígenes; mas entre cristãos e indígenas. Cristianizado o brasilíndio, entra no grêmio nacional, faz parte da comunidade portuguesa". Portanto, de acordo com o texto "Manoel da Nóbrega e São Paulo de Piratininga", de autoria de Tito Lívio Ferreira, o elemento que distinguiria os indígenas com a cidadania portuguesa seria a religiosidade católica, a ser difundida entre os gentios das terras coloniais pelos membros da Companhia de Jesus.

No entanto, o trabalho jesuítico não ficaria apenas no plano religioso. Foi Nóbrega o disseminador do plano de expansão territorial da Coroa portuguesa em terras brasileiras. O maioral da Companhia de Jesus teria escrito o seguinte a Dom João III no ano de 1553: 
para cumprir com a devoção de Vossa Alteza e com os desejos que em Nosso Senhor tenho destas partes serem favorecidas dêle, somente lhe direi alguma coisa desta Capitania de São Vicente onde a maior parte da Companhia residimos, por ser ela a terra mais aparelhada para a conversão do gentio, que nenhuma das outras, porque nunca tiveram guerra com os cristãos, e É POR AQUI A PORTA E O CAMINHO MAIS CERTO E SEGURO PARA ENTRAR NAS GERAÇÕES DO SERTÃO, de que temos boas informações". (grifo do autor)(A Igreja... 1955: 50)

De fato, o texto de Ferreira refere-se a Nóbrega como o primeiro a tecer considerações, ainda no ano de 1554, sobre os perigos decorrentes do Tratado de Tordesilhas, que facilitava a penetração dos espanhóis em terras portuguesas. Por isso, Nóbrega teria defendido a vigilância, defesa e o "expansionismo da obra da catequese "nos sertões do Paraguai'”. Aliás, essa teria sido uma das motivações da fixação no planalto, havendo, inclusive, "várias alusões (na documentação) em torno da Igreja de São Paulo, que falam de modo eloqüente deste seu descortinado propósito". (A Igreja... 1955: 31)

De acordo com os textos analisados, Nóbrega e os demais jesuítas a ele subordinados foram os primeiros bandeirantes das terras paulistas. Suas intenções e ações precederam e profetizaram o bandeirantismo de muito tempo depois. Qualidades consideradas próprias dos caçadores de índios e metais preciosos não faltavam aos membros loiolanos, "síntese dos sentimentos de fé, tenacidade, bravura e abnegação".

É interessante notar que, logo após o texto dedicado à obra de Nóbrega, a coletânea traz um fragmento do livro Paulistíadas, de Enzo Silveira, e também do poema "O Bandeirante", de Olavo Bilac ${ }^{5}$. Há uma clara intenção de se estabelecer relações entre as representações bandeirantes desses textos e a vida e obra de Nóbrega, relatadas nos vários outros artigos.

\footnotetext{
5 "Sete anos: combatendo índios, febres paludes/ Feras, reptis, — contendo sertanejos rudes,/ Dominando o furor da amotinada escolta .../ Sete anos!... ei-lo de volta, enfim, com seu tesouro! / Com que amor, contra o peito, a sacola de couro / Aperta, a transbordar de pedras verdes! - volta ... / Mas um desvão da mata, uma tarde de sol posto, / Pára. Um frio livor, se lhe espalha no rosto... / É a febre: o Vencedor não passará dali! / É a febre: é a morte. / E o Herói, trôpego e envelhecido, / Roto, e sem forças, cai junto do Guaicuí .../ Na terra que venceu há de cair vencido".
} 
O texto de Tito Lívio Ferreira anota claramente o bandeirantismo profético de Nóbrega quando diz:

Padre Manoel da Nóbrega profetiza: 'É por aqui a porta e o caminho mais certo e seguro para entrar nas gerações do sertão', porque antevê, no seu espírito arguto, os bandeirantes rumo ao oeste, na formidável jornada do devassamento da terra brasileira, meio século antes dos paulista começarem a formigar por todos os quadrantes do continente.(...) Também na carta de 15 de junho de 1553 reafirmara a constante de seu pensamento, sobre a centralização de poderes nas mãos do rei, para unificação territorial brasileira. (A Igreja... 1955: 50)

$\mathrm{Na}$ verdade, trata-se de uma leitura histórica orientada pelo "destino manifesto" paulista: ser a locomotiva da nação ${ }^{6}$.

Ainda sobre a ação missionária de Nóbrega, outros feitos são caracterizados em favor da formação do território nacional brasileiro. Destacam-se, por exemplo, sua atuação no Tratado de Iperoig, quando foi selada a paz com os tamoios (aliados aos franceses), e também o assalto aos franceses na Guanabara, quando os expulsou daquela região.

O território da província portuguesa do Espírito Santo para baixo estava ameaçado agora de desagregação, com a presença dos franceses na Guanabara. Urgia desalojá-los dali definitivamente.

era o pensamento inflexível de Nóbrega, senhor profeta do futuro do Brasil. Neste momento, pela última vez, sua figura ia sobrepujar a de todos; ele ia representar no palco histórico a última epopéia de sua via épica. Preparou a luta e assumiu a responsabilidade dela. Com arrojo

\footnotetext{
6 "Não terá sido sem particular desígnio da Providência. Se de São Paulo partiram os destemidos bandeirantes, que, deslocando o meridiano de Tordesilhas, alargaram consideravelmente as fronteiras da então colônia portuguesa - em que outros ombros mais robustos poderia descansar a responsabilidade de manter íntegro o território da nova nação que surgia no continente americano? A que outros braços mais afeitos ao manejo das armas se havia de confiar a defesa da terra e da gente brasileiras, entregues doravante à sua própria sorte? E em que outros peitos mais fundo se radicara a invicta paixão da liberdade?" Discurso proferido por ocasião da comemoração da Independência do Brasil, provavelmente de Dom Carlos Motta, s/data.
} 
admirável, dispõe-se a desfalcar a defesa de São Vicente, a fim de engrossar a tropa a seguir para o Rio. Por seu intermédio, o mais adiante glorioso Estado de São Paulo ia dar tudo que tinha em favor da unidade nascente da nossa pátria.(A Igreja ... 1955: 57)

Com base nesses atos, pode-se dizer que Nóbrega é, para os autores ora analisados, o fundador da Nação na representação dominante que conhecemos: seu território e sua unidade religiosa. Para completar o quadro, falta ainda considerar a formação do povo nacional, da sociedade brasileira em seus aspectos social e moral. Aqui também a obra jesuítica teria sido de destaque.

Evidentemente o povo nacional em formação era composto por índios e mestiços catequizados pelos jesuítas e que estabeleceram alianças com o colonizador português. Antonio de Arruda Camargo anota que o cacique Tibiriça, sogro de João Ramalho, é considerado a origem simbólica desse povo em formação. "Martim Afonso - nome que adotou quando recebeu o batismo, em homenagem ao grande amigo, cujas virtudes tanto admirava - Tibiriça é o encadeamento dos fatos. É o tronco, o primeiro varão da terra. A origem do povo paulista." (A Igreja... 1955: 61)

Aqueles considerados rebeldes ao cristianismo e às intenções dos colonizadores eram desqualificados como povo nacional. Serão estrangeiros em suas próprias terras, caçados, guerreados e mortos, como no episódio da Guerra dos Tamoios. O plano colonizador de Nóbrega apresentava, pois, a intenção de catequizar e aliciar para o trabalho os milhares de índios do Novo Mundo. Assim, Ferreira analisa o Plano de Jesuíta Provincial:

Nos seus aspectos fundamentais o plano nobreguense quer servir à civilização brasileira: combate à antropofagia e nomadismo indígena; estabelecimento da monogamia e do trabalho agrícola; autoridade civil e educação em bases cristãs. O plano de Nóbrega foi executado em parte por Duarte da Costa. Mem de Sá não lhe opôs reservas algumas. E daí a perfeita compreensão e unidade de vistas entre o governador do Brasil e o provincial da Companhia. (A Igreja... 1955: 56).

Outros ações envolvendo os missionários poderiam ser destacadas, como por exemplo, os esforços dos membros da Companhia de Jesus para a formação a uma língua geral do povo nacional. Por isso, o seu principal, o Padre Manuel da Nóbrega, é considerado um verdadeiro estadista, o primeiro estadista 
brasileiro. Todo esse conjunto de intenções e ações proféticas revelam ou estão envoltos na representação do "destino manifesto paulista". No plano historiográfico, essa representação apresenta o Estado de São Paulo como o sentido e, ao mesmo tempo, o sujeito histórico de toda realização e grandeza nacional. Tais elementos são perceptíveis nos textos analisados, por exemplo como destaca Tito Lívio Ferreira:

Iniciado com Tomé de Souza e prolongada até Mem de Sá, cerca de vinte anos, a obra de Nóbrega não tem paralelo na história do Brasil e na História de São Paulo. E São Paulo foi fundada por Manoel da Nóbrega, por ser o posto-chave da colonização e da catequese. (A Igreja... 1955: 58).

Ou seja: São Paulo não se tornou apenas o “posto-chave”, ele já o era antes da escolha: este era o seu destino.

Como se vê, em A Igreja dos Quatro Séculos de São Paulo - 1554-1954, a análise da presença da Igreja nos quatro séculos de São Paulo foi reduzida ao período colonial, com destaque para os seus primórdios e a atuação de Manuel

92 da Nóbrega na colônia portuguesa. Os demais períodos, o imperial e o republicano, carecem de textos analíticos. Quanto ao período imperial, temos um único texto de dimensões reduzidas e que aparece separado, na estrutura do livro, dos demais textos de análise histórica. Para o período da República não há textos analíticos. Por quê ?

Ao tentar responder à questão, podemos levantar dois argumentos, ainda que inseguros:

a) o período inicial da presença da Igreja Católica no Brasil, em particular dos jesuítas na Capitania de São Vicente, ajusta-se mais facilmente com as representações tradicionais do passado paulista, em especial com seus signos mais fortes: o bandeirantismo (deslocado de sua singularidade histórica e estendido a uma representação total do passado paulista, com suas idéias fortes - bravura, independência, modernidade, etc.) e São Paulo - Nação (o Estado de São Paulo considerado a locomotiva do país, lugar original das iniciativas que formaram o Brasil: seu território, seu povo, seu espírito moral, sua independência e sua liberdade republicana);

b) por outro lado, tal período da história da Igreja no Brasil fortalece a autocompreensão ultramontana católica dos anos 50 naquilo que essa representação apontava como características de todo o mundo católico: a ação 
catequética (os anos 50 no Brasil são especialmente ricos em iniciativas favoráveis ao catecismo popular), a reforma dos costumes (era o objetivo principal da Ação Católica, levando os "verdadeiros" sentimentos cristãos até a população, retirando-lhe ou reformando sua religiosidade devocional) e a aliança com o Estado (tal como a Igreja, o Estado e a família eram considerados modelos de sociedades perfeitas a serem orientadas moralmente pela Igreja).

Mesmo o pequeno texto intitulado "A Igreja em São Paulo no Período Imperial" aponta para os elementos apresentados acima: notam-se várias críticas às teorias liberais no interior da Igreja - cujo expoente da época era o Padre Feijó -, consideradas um desvio do verdadeiro credo católico. O Cônego Luiz Castanho de Almeida, autor do texto, inclusive caracteriza como atitude sem propósitos a idéia da separação entre a Igreja e o Estado.

Ao analisar as realizações da Igreja durante o período imperial, Almeida destaca as atuações dos dois principais bispos reformadores ultramontanos da segunda metade do séculos XIX: Dom Antonio Joaquim de Melo (1852-1861) e Dom Lino Deodato de Carvalho (1874-1894). O primeiro foi o responsável pelas mudanças na formação dos membros do clero paulista e parte do clero brasileiro, ao propugnar a criação de seminário na cidade de Itu, trazendo como docentes um grande número de católicos pertencentes às ordens mais afinadas com a ortodoxia defendida por Roma. Já Dom Lino Deodato de Carvalho é, entre outros feitos, o responsável pela introdução da devoção ao "Sagrado Coração de Jesus" e das "Filhas de Maria" no Brasil que, com o passar do tempo, substituíram as antigas associações populares devocionais características do período anterior. Essas novas práticas devocionais e associativas do catolicismo romanizado ainda eram, na década de 50 deste século, as mais freqüentes nos meios populares.

Com relação ao período republicano, há no conjunto dos textos analisados um grande silêncio. É difícil encontrar uma resposta que seja razoavelmente convincente. Dentro de nossa linha de análise, faremos apenas conjecturas. O período republicano dificilmente serviria à construção da representação histórica positiva que verificamos até agora, uma vez que, no tocante à religião, alguns fatos marcantes dentro da República foram: a separação oficial entre a Igreja Católica e o Estado, a liberdade de culto (o liberalismo religioso) e as contendas entre as duas instituições, sendo constante o ataque da Igreja ao agnosticismo presente nas instituições e no meio elitista republicano. 
É bem verdade que durante todo o período republicano e após a primeira década do século XX, ocorrera uma sensível melhora no relacionamento entre as elites que comandavam o Estado brasileiro (principalmente o Estado de São Paulo) e a hierarquia católica. No entanto, essa assertiva não é suficiente para a construção de uma imagem positiva de tal relação. De uma maneira geral, durante o primeiro período republicano, as instituições e os costumes das elites são condenados pela Igreja.

Bastante diferentes são as relações entre as duas esferas após os anos 20 e principalmente após a década de 30, na Era Vargas, quando verificamos uma grande aproximação entre Igreja e Estado, colaborando mutuamente na construção do regime autoritário. Nesse processo destacam-se duas personalidades não originárias de São Paulo: o Cardeal Leme e Getúlio Vargas. Aparentemente o destino histórico do Brasil fugia das mãos paulistas. Tratava-se, na verdade, de uma continuidade histórica com outros caminhos. A Igreja paulista não era protagonista desse novo processo de entendimento, aliás, colocou sérios obstáculos a ele tanto no episódio de 1930 como no de 1932, quando não mediu esforços para combater ao lado dos "paulistas". Mas, mais importante era que a hierarquia católica nutria uma vontade de distanciamento em relação ao varguismo, não apenas em função da crise conjuntural que viveu o governo federal, que resultou no suicídio de Getúlio Vargas, como principalmente em relação à memória do período ditatorial do Estado Novo, com o qual colaborou nacionalmente, mas que após a Segunda Guerra e a derrota do fascismo, procurava distanciar-se daquelas vinculações ideológicas. O segundo governo de Vargas (1951-1954) foi bastante combatido pela imprensa católica de São Paulo, particularmente através de seu importante jornal "O Legionário".

Portanto, nem a Primeira República, nem a Segunda República são períodos ideais para a representação histórica presente nos textos da coletânea $A$ Igreja dos Quatro Séculos de São Paulo: 1554 - 1954.

Concluindo, podemos dizer em primeiro lugar, o livro possui, em sua análise histórica, as características da historiografia e das representações do passado da elite paulista: o espírito bandeirante e a vocação nacional dos paulistas (no decorrer da coletânea, é significativa a reprodução de figuras e retratos de bandeirantes paulistas bem como de instrumentos geralmente vinculados a sua imagem); em segundo, a referida obra é claramente marcada pelo contexto, ou seja, as comemorações pelo IV Centenário da cidade de São Paulo, a construção da nova Catedral da Sé e os novos movimentos de catequese inspirados no catolicismo romanizado, bem como por uma rejeição à herança varguista ou pelo medo da 
força social deste poder político-teológico, que em uma visão perspectiva do passado apresentava delineamentos para envolver a sociedade em uma ideologia sacralizada, mas não propriamente controlada pela Igreja Católica.

Assim, instaura-se um passado católico em São Paulo relacionado com a seleção dos momentos e de determinados elementos históricos, recaindo a preferência sobre a presença dos jesuítas em terras paulistas na primeira fase colonial e sobre a fundação oficial da cidade de São Paulo. Nos demais períodos, são escolhidos os fatos e atores que não chocam a representação geral que, entre outras coisas, procura mostrar a força perene da religiosidade católica em terras paulistas e brasileiras.

Trata-se, portanto, de uma imagem histórica descontínua e, no entanto, linear. Podemos também dizer que é uma história elitista, pois retrata tão somente a visão e os feitos de uma parcela da hierarquia católica, o que lhe imputa um caráter fatalista e triunfalista. A iconografia apresentada ao longo da obra confirma nossas afirmações: retratos de membros da elite eclesiástica paulista, de reis, governadores e papas e seus símbolos.

As camadas populares não estão presentes nessa história, a não ser como vencidos. Sua representação ocorre através da figura do índio catequizado e aliado dos colonizadores. Aos membros do baixo clero, índios, negros, trabalhadores

pobres e mulheres que de fato foram responsáveis, ao longo dos séculos, pela expansão da religião católica no Brasil foi concedido apenas o silêncio.

\section{Referências Bibliográficas}

A Igreja dos Quatro Séculos de São Paulo: 1554-1954. São Paulo: Editora Documentários Ltda, 1955.

FARIAS, Damião Duque de. Em defesa da ordem: aspectos da práxis católica no meio operário em São Paulo (1930-1945). São Paulo: História Social USP, Ed. Hucitec, 1998.

História da Igreja no Brasil: ensaio de interpretação a partir do povo. São Paulo: Ed. Paulinas; Petrópolis: Vozes, 1992, $3^{\text {a }}$ edição.

LUSTOSA, Oscar F. A Igreja Católica no Brasil República. São Paulo: Paulinas, 1991.

MAINWARING, Scott. Igreja e política no Brasil: (1916-1985). São Paulo: Brasiliense, 1989.

VILLAÇA, Antônio Carlos. O pensamento católico no Brasil. Rio de Janeiro: Zahar, 1975.

WERNET, Augustin. A igreja paulista no século XIX. São Paulo Ática, 1987. 